\title{
THE „MOTIVATIONAL CLIMATE IN PHYSICAL EDUCATION SCALE” IN GREEK EDUCATIONAL CONTEXT
}

\author{
F. Filippou ${ }^{1}$, Gr. Masadis' ${ }^{1}$ O. Kouli ${ }^{1}$, Ch. Konstantinidis1, \\ E. Bebetsos ${ }^{1}$, V. Derri ${ }^{1}$, \& E. Samara ${ }^{2}$ \\ ${ }^{1}$ Department of Physical Education and Sport Science, \\ Democritus University of Thrace, Greece \\ ${ }^{2} 5$ th Gymnasium of Katerini, Greece
}

\begin{abstract}
The principal aim of this study was to confirm the "Motivational Climate in Physical Educational Scale" (Soini, et al, 2014) in a Greek elementary school context. The internal consistency of the MCPES was also examined. 184 students of the last two grades of primary schools were participated the survey. The Greek version (Masadis, et al, 2019) of MCPES was used. The validity and reliability of the questionnaire were checked by performing a confirmatory factor analysis and an internal consistency analysis. Also, descriptive statistics, T-test and One-way Anova analysis were used. From the analysis we came to the following conclusions: $a$. the Cronbach's $\alpha$ values were high and the loadings of the confirmatory factor analysis supported the factors of the original scale. $b$. The factor "task involving" presents the highest $M$ while the factor "ego involving" the lowest. c. Gender turns out an element that differentiates the factors "task involving", "autonomy" and "go involving".
\end{abstract}

Keywords: confirmatory analysis, reliability analysis, elementary school, psychometric properties

\section{INTRODUCTION}

Physical Education is an invaluable subject in primary and secondary school curriculum because of its great potential for students' physical, mental, emotional and social development (Bournelli et al., 2012). Despite tangible benefits that derive from Physical Education and after- school sport activities students, as they grow older, become more reluctant to participate and gradually spare no effort during Physical Education lessons (Iconomescu, Mindrescu, Popovici, 2018). It is, therefore, crucial the school climate and the rapport teachers build up with students.

The principal aim of this study was to confirm the "Motivational Climate in Physical Educational Scale" (Soini, et. al, 2014) in a Greek elementary school context. The internal consistency of the MCPES was also examined.

\section{METHODOLOGY}

\section{Participants}

184 students of the last two grades of primary schools were participated the survey from ten (4) elementary school entire Greece (Imathia, Chanea, Kozani, Rhodes). The selection of schools was random.

\section{Measurement}

The Greek version (Masadis, et al, 2019) of Motivational Climate in Physical Educational (Soini, et al, 2014) was used. The questionnaire consists from eighteen (18) items researching the four parameters (Autonomy, Social relatedness, Task involving and Ego involving) of motivational climate during the lesson of physical education.

\section{Procedure}

The survey organizers had to ask for permission from the Ethics Committee of Democritus University of Thrace and the Minister of Education in order to carry out the survey at schools. Approval was granted by the University in February 2019 and by the Ministry of Education a month later.

\section{Data analysis}

The validity and reliability of the questionnaire were checked by performing a confirmatory factor analysis and an internal consistency analysis. Also, descriptive statistics, T-test and One-way Anova analysis were used.

\section{RESULTS}

Confirmatory analysis

A confirmatory factor analysis was performed on the 
four subscales of the (MCPES). The method of estimating parameters is that of maximum likelihood (Bentler, 1990). The hypothesized model consists of four latent variables, namely "Autonomy", "Social relatedness", "Task involving" and "Ego involving".

The fit indices which were considered and their acceptable values are: namely minimum discrepancy
(CMIN or $\chi^{2}$ ), degrees of freedom (D.F.), minimum discrepancy divided by the degrees of freedom $\left(\chi^{2} /\right.$ d.f.) $<5$, Root Mean Square Error of Approximation (RMSEA) <.08, Standardized Root Mean Square Residual (SRMR) <.05, incremental indices Comparative Fit Index (CFI) $>.90$, and Normed Fit Index (NFI) >.90 (Bentler, 1990; McDonald \& Marsh, 1990) and Goodness of Fit Index.

Table 1. Model Fit Indices

\begin{tabular}{|l|c|c|c|c|l|l|l|l|l|}
\hline & $\mathbf{N}$ & $\mathbf{X}^{\mathbf{2}}$ & $\mathbf{D F}$ & $\mathbf{X}^{\mathbf{2}} / \mathbf{D F}$ & $\mathbf{N F I}$ & $\mathbf{C F I}$ & $\mathbf{R M S E A}$ & SRMR & GFI \\
\hline Model & 184 & 189.96 & 129 & 1.47 & .94 & .98 & .046 & .041 & .90 \\
\hline
\end{tabular}

The results of the confirmatory factor analysis de- Reliability analysis

monstrated that the hypothesized model produced Factors' reliability control was carried out by calcua significant chi-square, $\chi^{2}(189.96,129)=1.47$, lating the values Cronbach's $\alpha$, for each factor. As $\mathrm{p}<0.05$. The NFI and CFI were found to be .94 and appears in table 3 , the values of the factors were sat.98 respectively. The RMSEA was also considered isfactory ( $\mathrm{a}>.85)$.

to assess the degree of $\mathrm{ft}$ of the model. The RMSEA Means and standard deviations of the main varivalue for the hypothesized model was found to be ables for overall sample, as well as for males and .046 and SRMR=.041 (Table 1).

females are shown in Table 2. Generally, students perceived a high task-involving climate, relatively positive autonomy climate, moderate relatedness and weak ego-involving.

Table 2. Mean, Standard Deviation, Cronbach's $\alpha$ \& gender differences

\begin{tabular}{|l|c|c|c|c|c|c|c|c|l|l|}
\hline & \multicolumn{2}{|c|}{$\begin{array}{c}\text { Overall } \\
\mathrm{n}=184\end{array}$} & \multicolumn{2}{c|}{$\begin{array}{c}\text { Male } \\
\mathrm{n}=101\end{array}$} & \multicolumn{2}{c|}{$\begin{array}{c}\text { Female } \\
\mathrm{n}=83\end{array}$} & \multicolumn{2}{c|}{ Gender differences } & \\
\hline & $\mathbf{M}$ & SD & $\mathbf{M}$ & SD & $\mathbf{M}$ & $\mathbf{S D}$ & $\mathbf{F}$ & $\mathbf{p}$ & $\mathbf{n 2}$ & alpha \\
\hline Task & 4.03 & .94 & 3.81 & 1.05 & 4.29 & .69 & 12.8 & .001 & .08 & .89 \\
\hline Autonomy & 3.24 & 1.02 & 3.44 & .99 & 2.99 & .99 & 9.40 & .001 & .05 & .89 \\
\hline Relatedness & 3.08 & 1.12 & 2.75 & 1.13 & 3.49 & .98 & 22.4 & .001 & .11 & .90 \\
\hline Ego & 2.43 & 1.07 & 2.78 & 1.20 & 2.02 & .71 & 24.6 & .001 & .12 & .85 \\
\hline
\end{tabular}

Differences according to gender

To check whether there were statistically important differences on gender, T-tests for independent samples were performed. Follow-up t-test showed that male students reported higher autonomy and ego involvement compared to female students. Female students reported higher task involving climate and relatedness (Table 2).

\section{DISCUSSION AND CONCLUSION}

The aim of this study was to Confirm the questionnaire "Motivational Climate in Physical Educational" (MCPES) (Soini, et al., 2014) in Greek educational context. Another objective was to look into gender as a differentiation factor of motivational climate.

Regarding the validity of the factors and the struc- ture itself, the "Motivational Climate in Physical Educational" has shown a structure of four oblique factors, coinciding with the findings of Soini, et al. (2014). As far as reliability is concerned, results have shown the required internal consistency and temporal stability of the scale, with results similar to the findings of Soini, et al. (2014) and Jaakkola, et al (2015).

The gender proves a differentiation factor of motivational environment. Males, in particular, are more independent and self-oriented unlike females who are more sociable and task- oriented.

From the analysis we came to the following conclusions:

a. the Cronbach's $\alpha$ values were high and the loadings of the confirmatory factor analysis supported the factors of the original scale. 
b. The factor "task involving" presents the highest $\mathrm{M}$ while the factor "ego involving" the lowest.

c. Gender turns out an element that differentiates the factors "task involving", "autonomy" and "ego involving".

d. Class attendance does not constitute differential factor.

\section{REFERENCES}

Bentler, P.M. (1990). Comparative fit indexes in structural models. Psychological Bulletin, 107, 238-246.

Bournelli, P., Koutsouki, D., Zografou, M., Aggelonidis, I., Chatzopoulos, D., \& Agalianou, O. (2012). Physical Education for $3^{\text {rd }} \& 4^{\text {th }}$ elementary school grades. Teacher's book. Athens. Textbook Publishing Organization.

Iconomescu, M., Mindrescu, V., \& Popovici, I. (2018). A comparative study

regarding secondary school students' satisfaction degree regarding the physical education class in Roma- nian and in Turkey. SHS Web of Conferences 48, 01028, https://doi.org/10.1051/shsconf/20184801028

Jaakkola, T., Wang, J., Soini, M., \& Liukkonen, J. (2015). Students' Perceptions of

Motivational Climate and Enjoyment in Finnish Physical Education: A Latent Profile Analysis. Journal of Sports Science and Medicine, 14(3):477-483.

McDonald, R.P., Marsh, H.W. (1990). Choosing a multivariate model: noncentrality and goodness of fit. Psychological Bulletin, 107:247-255.

Masadis, G., Filippou, F., Bebetsos, E., Kouli, O., Petanidis, \& D., Derri, V. (2019).

Factorial Structure and Reliability of Motivation's Scale in P.E. at Elementary School Lessons. $27^{\text {th }}$ International Congress on Physical Education \& Sport Science 10-12 May 2019/ Komotini/Greece.

Soini, M., Liukkonen, J., Watt, A., Yli-Piipari, S., \& Jaakkola, T. (2014). Factorial validity and internal consistency of the motivational climate in physical education scale. Journal of Sports Science \& Medicine, 13(1):137-144. 